DOI: http://doi.org/10.21698/simi.2018.ab17

\title{
TESTING PILOT-SCALE BORON-DOPED DIAMOND ELECTRODES (BDDE)-BASED ELECTROCHEMICAL MODULE FOR DRINKING WATER TREATMENT
}

\author{
$\underline{\text { Adina Pacala }^{1}}$, Katalin Bodor ${ }^{1}$, Ilie Vlaicu ${ }^{1}$, Florica Manea ${ }^{2}$ \\ ${ }^{1}$ Aquatim SA Timisoara,11/A, Gheorghe Lazar Street, code 300081, Timisoara, \\ adina.pacala@aquatim.ro, katalin.bodor@aquatim.ro, ilie.vlaicu@aquatim.ro, Romania \\ ${ }^{2}$ Department of Applied Chemistry and Engineering of Inorganic Compounds and \\ Environment, Faculty of Industrial Chemistry and Environmental Engineering, 6 Vasile Parvan \\ Street, code 300223, Timisoara, florica.manea@upt.ro, Romania
}

Keywords: advanced drinking water treatment, ammonium removal, boron-doped diamond electrodes, electrochemical oxidation, pilot-scale

\section{Introduction}

The presence of ammonium in groundwater represents a public health issue because of its own adverse problems including toxicity towards some aquatic organisms in surface waters, increase disinfectants requirement, and/or cause biological nitrification in water distribution systems. The maximum allowance concentration (MAC) for ammonium in drinking water is $0.5 \mathrm{mg} / \mathrm{L}$ and higher concentrations require its removal. Thus, there is a need for efficient ammonium removal technologies suitable for large scale water treatment systems as well as very small point-of-use (POU) treatment systems within homes. A unique feature of most POU systems is the need for chemical-free treatment. Electrochemical processes exhibit a great potential to be used for the drinking water treatment and very promising results have been reported for the boron-doped diamond (BDD) based electrochemical oxidation process. In this study, BDD-based electrochemical oxidations at the laboratory and pilot-plant scales are assessed for the ammonium-containing drinking water treatment.

\section{Materials and methods}

Two types of real ammonium containing groundwaters were used for testing electrooxidation (EO) module of the flexible pilot-plant with the complete simplified flow-chart presented in Figure 1. EO module by type of DiaCell ${ }^{\circledR}$ kit (Switzerland) consisted of boron-doped diamond electrodes as anode and cathode, for which the ratio between volume and electrode area is 10 . The matrices of the groundwaters differ mainly through the presence of iron and manganese over the maximum allowance limit. Prior to pilot-scale testing, the BDD-electrodes based electro-chemical process was assessed at the laboratory scale. 


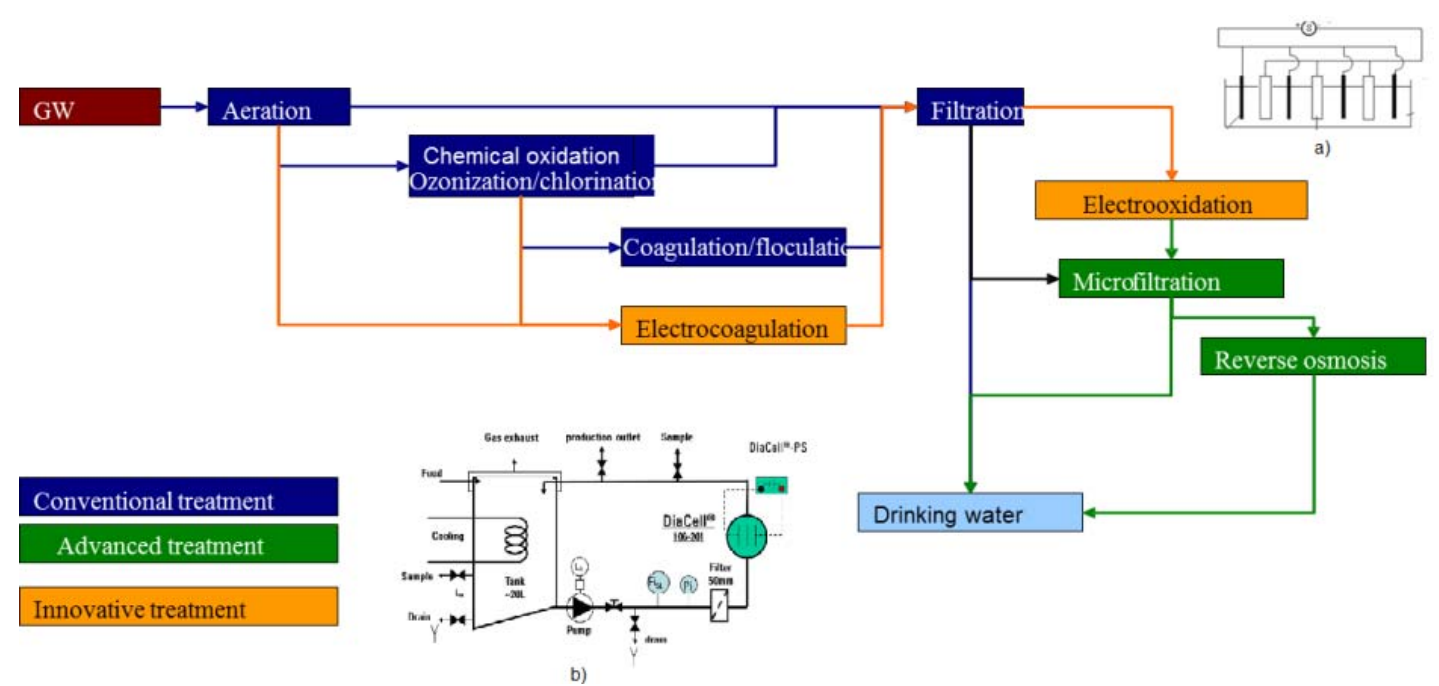

Figure 1. The simplified flow-chart of flexible pilot-plant including EO module; Insets: a)-electrochemical arrangement at the laboratory scale: b)-EO unit within the pilot scale

\section{Results and conclusions}

The BDD-electrodes based electrochemical process operated at the laboratory scale was found to be very effective for ammonium removal for all tested groundwater sources, independently on the groundwater matrix. After maximum ten minutes of electrolysis at the current density of ranged between $25-100 \mathrm{~A} / \mathrm{m}^{2}$, the removal efficiency of ammonium was reached over $90 \%$. However, at pilot-scale, the process efficiency was affected by the groundwater matrix. The presence of iron and manganese in groundwater necessitates the application of high current density and implicit, high energy consumption and oxidation of iron and manganese occurred leading to the precipitates. To avoid the deposition of iron and manganese precipitates onto the electrode surfaces that inactivate them and block the electrochemical process, a specific geometry and arrangement of the electrodes should be assured. Also, the polarity reversion during the electrochemical process occurring allowed the electrode surface reactivation with a degree related to the iron and manganese content. However, a filtering step is required if iron and manganese are present in the groundwater. Taking into account the minimum conductivity value required to assure the operational conditions for electrochemical oxidation process, the conductivity was increased to $1000 \mu \mathrm{S} / \mathrm{cm}$ by adding $\mathrm{NaCl}$ solution, which led also, to $\mathrm{Cl}_{2}$ generation assuring the disinfection process. In conclusion, the pilot-scale testing represented a valuable tool in the treatability study of drinking water from various sources, providing very useful information to design the technological flow for the drinking water treatment.

\section{Acknowledgements}

This work was supported by a grant of the Romanian Ministry of Research and Innovation, CCCDI-UEFISCDI-2017-0245/26PCCDI/2018, within PNCDI III. 